\title{
LA DOCTRINA DE LA INCONMENSURABILIDAD EN PAUL FEYERABEND: UNA OBJECIÓN CONTRA UNA PARTICULAR CONCEPCIÓN DE RACIONALIDAD CIENTÍFICA
}

\author{
TERESA GARGIULO \\ Conicet (Consejo Nacional de Investigaciones Científicas y Técnicas) \\ UnCuyo (Universidad Nacional de Cuyo), Argentina
}

\begin{abstract}
RESUMEN. La inconmensurabilidad ha ocasionado innumerables controversias y debates. En estos parece ser unánime la interpretación de tal doctrina como una objeción contra la objetividad, el realismo y el progreso científico. Ahora bien, este marco hermenéutico es estrecho para poder comprender la intencionalidad de Paul Feyerabend al formular su doctrina de la inconmensurabilidad. Pues éste no pretendió cuestionar nunca a dichas nociones en cuanto tales sino únicamente mostrar cuán vano resulta ser el intento del neo-positivismo y del racionalismo popperiano por definirlas. En un sentido positivo sostenemos que la inconmensurabilidad en Paul Feyerabend impide o evita retomar, a la hora de definir aquellas nociones, las dialécticas propias del positivismo lógico o del racionalismo crítico. Nuestra intención en este trabajo es exponer su tesis de la inconmensurabilidad como un cuestionamiento a un modo particular de concebir la racionalidad científica y a sus consecuentes nociones de objetividad, progreso y realismo científico.
\end{abstract}

PALABRAS CLAVE: Feyerabend, inconmensurabilidad, criterio de demarcación, relación ciencia-metafísica, Kuhn.

\section{The Doctrine of Incommensurability in Paul Feyerabend.}

\section{An Objection Against a Particular Conception of Scientific Rationality}

ABSTRACT. Incommensurability has caused many controversies and debates. In these debates seems to be unanimous the interpretation of that doctrine as an objection to objectivity, realism and scientific progress. Now this is a narrow hermeneutical framework for understanding the intention of Paul Feyerabend when formulating his doctrine of incommensurability. Because he was never intended to challenge such notions in themselves but only to show how vain turns out to be the neo-positivism and Popperian rationalism's attempt to define them. In a positive sense we argue that incommensurability, according to Paul Feyerabend, prevents or impedes when we comes to define those notions return to dialectical of logical positivism or critical rationalism. Our intention in this paper is to present his thesis of incommensurability as a challenge to a particular way of conceiving scientific rationality and its consequent notions of objectivity, progress and scientific realism.

KEY WORDS: Feyerabend, incommensurability demarcation criterion, relationship between science and metaphysics, Kuhn.

\section{INTRODUCCIÓN}

En el año 1962 con la aparición de La estructura de las Revoluciones Científicas de Thomas Kuhn (1970a) y el artículo Explicación, Reducción y Empirismo de Paul Karl Feyerabend $(1962 / 1989)^{1}$, irrumpe en el campo de la filosofía de la

1 Para facilitar la lectura, las citas de las obras de Paul Feyerabend tendrán doble fecha. La primera se refiere al año de la primera publicación y la segunda a la publicación consultada. 
ciencia una de las tesis más controversiales durante la segunda mitad del siglo $\mathrm{XX}$, a saber, la tesis de la inconmensurabilidad.

Las diversas comprensiones que dichos autores tienen acerca de esta tesis, así como la falta de un uso consistente y claro de ella en la abundante literatura que la discute, ha exigido una ardua tarea analítica que ha permitido distinguir las distintas versiones y sentidos que puede adoptar la doctrina de la inconmensurabilidad. En esta tarea se destaca el trabajo de Sankey y Hoyningen-Huene (2001) quienes clasifican las distintas acepciones que adquiere la doctrina de doctrina de la inconmensurabilidad tanto en Kuhn como en Feyerabend. Por su parte, Hoyningen-Huene ha profundizado particularmente el desarrollo y la evolución de esta tesis en la obra de Kuhn. En línea con este trabajo de esclarecimiento Oberheim (2006, 77-115) ha explicado las diferencias que existen entre la tesis popperiana de la inconsistencia lógica y la doctrina de la inconmensurabilidad de Paul Feyerabend. Finalmente, cabe destacar el trabajo de Perovich (1991) quien tiene el mérito de haber subrayado el signo distintivo de la doctrina de la inconmensurabilidad de Feyerabend, a saber, la relación de inconsistencia ontológica entre teorías sucesivas.

No obstante, y a pesar de ésta y otra abundante literatura especializada, parece quedar una parcela inédita de estudio en torno a la doctrina de la inconmensurabilidad de Paul Karl Feyerabend. Pues en ella no se atiende a lo que consideramos un aspecto esencial de su doctrina, a saber, al carácter de objeción que ella guarda respecto a un modo particular de concebir la racionalidad científica y a sus consecuentes nociones de objetividad, progreso y realismo científico. Feyerabend con su doctrina de la inconmensurabilidad da cuenta de la impotencia de las dialécticas con las que el positivismo lógico y el racionalismo crítico pretenden fundamentar o definir aquellas nociones. Ahora bien, si no se destaca este cuestionamiento radical que implica su doctrina de la inconmensurabilidad existe el riego de acceder a una comprensión fragmentaria e incompleta de esta tesis del vienés.

En continuidad con las líneas de investigación ya mencionadas procuraremos analizar esta particular dimensión de la doctrina de la inconmensurabilidad de Feyerabend. Pues desde este nuevo horizonte o perspectiva explicaremos cómo su tesis de la inconmensurabilidad ontológica - tal cual ha sido ya definida por Perovich (1991, p. 319) — se ordena, en definitiva, a mostrar la impotencia del positivismo y del racionalismo para definir la ciencia y sus consecuentes nociones de progreso y realismo científico. En este sentido, creemos que el valor del presente estudio no radica en la originalidad o la novedad de su tesis sino, más bien, en la precisión con la que se expresa la intencionalidad o el fin último que Feyerabend persigue con su crítica.

El objetivo de la doble fecha es dar cuenta de un orden cronológico de las publicaciones y, al mismo tiempo, remitir al lector a los lugares precisos donde pueda cotejar las citas textuales, las paráfrasis y las referencias generales. 
Para dar cuenta de esta tesis, en primer lugar, presentaremos la tesis de la inconmensurabilidad ontológica como la causa y explicación de sus demás versiones de inconmensurabilidad (1). Una vez comprendida la naturaleza ontológica de su tesis de la inconmensurabilidad analizaremos sus consecuencias (2). Primero, explicaremos cómo ella supone un cuestionamiento a los distintos intentos del positivismo y del racionalismo por definir el realismo científico (2.1) y finalmente a los mismos esfuerzos por explicar el progreso científico (2.2).

\section{LA INCONMENSURABILIDAD ONTOLÓGICA}

La doctrina de la inconmensurabilidad se inscribe en la tradición reconocida como historicista (Munévar 2006, 16) o 'Weltanschauungística' (Suppe, $1990,254)$ entre cuyos protagonistas principales pueden mencionarse a Toulmin, Kuhn, Hanson, Bohm y Paul Feyerabend. Todos ellos argumentan que aquellos elementos metafísicos o pre-racionales — que la Concepción Heredada recluía en el contexto de descubrimiento- son medulares en el contexto de justificación quedando así desdibujada la frontera que el positivismo lógico y el racionalismo crítico traza entre la metafísica especulativa y las ciencias naturales. Dentro de esta tradición, la inconmensurabilidad tal como fue pensada por Feyerabend y Kuhn amplia y enriquece las concepciones axiomáticas o metodológicas de la ciencia destacando los elementos metafísicos u ontológicos que la componen. La inconmensurabilidad demuestra que la ciencia no está constituida únicamente por elementos lógicos, observacionales y metodológicos; sino que los elementos metafísicos son un componente ineludible del quehacer científico.

En un contexto de cuestionamientos radicales a lo que se reconoce como la Concepción Heredada Feyerabend se aboca a demostrar las contradicciones y limitaciones que suponen tanto los intentos del neo-positivismo lógico como los del racionalismo crítico por establecer un criterio de demarcación que defina negativamente a la ciencia, es decir, deslindándola de todo elemento metafísico. El positivismo lógico concibe el principio de demarcación como un principio formal que debe ser desarrollado por la lógica inductiva, el racionalismo crítico, por su parte, lo plantea como un principio metodológico, particularmente lo identifica con la posibilidad de falsación. Pero ya sea que se conciba el principio de demarcación como un principio formal o metodológico Feyerabend asegura que en ambos casos se trata de un criterio vacío. Pues las barreras que se establecen para discriminar lo científico de lo no-científico, lo empírico de lo metafísico, lo objetivo de lo subjetivo, lo real de lo aparente... se construyen y desvanecen a lo largo de un complejo proceso histórico, es decir, a través de las múltiples ontologías que surcan la entera historia de la ciencia. Cada tradición, cada teoría científica sugiere una distinción particular y arbitraria entre lo científico y lo mítico, entre lo racional y lo irracional en función de la ontología o visión del mundo que la anima. 
John Preston asegura que el primer artículo donde Feyerabend expone el problema de la inconmensurabilidad — aunque sin hacer uso del término mismo-, es en Complementarity (1958) (Preston, 1997, 102-103). Eric Oberheim, quien ha hecho un estudio a partir de bibliografía exhaustiva y desde los mismos originales del epistemólogo, lo corrige y sostiene que ya en 1951, en la disertación de su tesis doctoral ${ }^{2}$, Feyerabend usa la noción de inconmensurabilidad para rechazar el rol que el empirismo lógico concede a las oraciones observacionales en la comprobación de las teorías (Oberheim, 2006, 169-170). Pero indudablemente - y tal como señala Hoyningen-Huene- donde Feyerabend hace una exposición sistemática de su doctrina de la inconmensurabilidad es en Explicación, reducción y empirismo (1962) (Hoyningen-Huene 2000a, 9).

La crítica que Feyerabend dirige contra el positivismo lógico, particularmente contra la teoría de la reducción de Nagel y la teoría de la explicación de Hempel y Oppenheim — con sus respectivos principios de deducibilidad ${ }^{3}$ y de estabilidad del significado ${ }^{4}$ - lo conduce a dar razón de la inconmensurabilidad existente entre teorías comprehensivas. Toda teoría - explica Feyerabend- en virtud de su ontología no sólo define un modo particular de ver la realidad sino que estable una manera de seleccionar $(1962 / 1989,108$, 77-78), disponer y explicar (1962/1989, 54; 1958/1981a, 31 y 77-78); la evidencia o hechos observacionales (1962/1989, 54, 73, 92 y 129), fija la significación que adquieren los términos teóricos y observacionales (1962/1989, 78; 1958/1981a,

2 Zur Theorie der Basissätze (Disertación del PhD) Universitäts Bibliothek Wien, (1951). No disponemos de su tesis doctoral, pues ésta aún no ha sido publicada. No obstante teniendo en cuenta los estudios realizados por Obeheim quien sostiene que "en su tesis doctoral Feyerabend usó la idea básica de inconmensurabilidad en el mismo sentido que la usó en 1954, 1958, y 1962» (Oberheim, 2006, 70, nos abocaremos al estudio de los artículos publicados en estos años. Además, se puede encontrar una versión abreviada de su tesis en el articulo An attempt at a realistic interpretation of experience (1958) (Feyerabend, 1958/1981a, 17-36).

Feyerabend en su tesis doctoral refuta particularmente el conservadurismo conceptual implícito en el principio metodológico de Heisenberg según el cual una vez que se establece conclusivamente un resultado experimental simultáneamente se constituyen las condiciones para los próximos desarrollos teóricos. Feyerabend prueba que estas condiciones a priori entorpecen el progreso de la ciencia al impedir el desarrollo de nuevos términos conceptualmente incompatibles (inconmensurables) con los de las teorías existentes.

3 El principio de la deducibilidad postula, según Feyerabend, que toda nueva teoría no es más que una consecuencia lógica de su predecesora. De aquí la posibilidad y la exigencia de explicar toda teoría mediante la reducción de sus principios a las leyes y principios de las teorías que la anteceden; y que las teorías en un determinado dominio sean consistentes en un sentido lógico estricto (Feyerabend, 1962/1989, 41-42, 62).

4 El principio de estabilidad del significado - tal como lo concibe el vienés- dicta que el significado de los principales términos observacionales permanecen intactos e invariables respecto al proceso de reducción o explicación. Los términos claves no cambian de significado al ser abarcados o reducidos a una nueva teoría Los términos observacionales de una teoría científica se reducen a una experiencia u observación común la cual garantiza la estabilidad de los significados de los términos observacionales (Feyerabend, 1962/1989, 41-42, 49, n. 11 y 62). 
31), crea los instrumentos de observación y medición, y codifica los modos en que los resultados deben interpretarse (1962/1989, 53-54, 77-78). De aquí que en la medida que las teorías estén informadas por una ontología distinta el conjunto de datos observacionales, términos, leyes o principios de una teoría resulten incompatibles o, más propiamente, inconmensurables con los de otra. Para Feyerabend la inconmensurabilidad revela la relación de inconsistencia que existe entre dos o más teorías sucesivas. «[U]na teoría es incompatible con otra si sus consecuencias ontológicas son incompatibles con las consecuencias ontológicas de la última» (1981d, xi). La causa última de la inconmensurabilidad es la ontología que atraviesa el contexto teórico como un todo.

Esta relación de inconmensurabilidad es lo que justamente impide para Feyerabend que una teoría sea reducida o explicada en los términos de sus sucesoras; y que el significado de sus términos permanezca invariable. Pues la transición de una teoría $\mathrm{A}$ a una teoría $\mathrm{B}$ implica un cambio más radical que la incorporación de A, sin modificación alguna, al contexto de B. Más bien, —explica el vienés- lo que tiene lugar es una sustitución de la ontología de A por la ontología de B (1962/1989, 39, 92 y 119; 1977, 364, n. 3)

Feyerabend en La Ciencia en una Sociedad Libre (1978) define la inconmensurabilidad en Kuhn como una relación multidimensional, mientras que desataca que inicialmente con su doctrina de la inconmensurabilidad se refiere de modo exclusivo a la imposibilidad de establecer relaciones lógicas de inclusión o reducción entre los conceptos y enunciados observacionales pertenecientes a distintas teorías (1978/ 1982, 74-75; 1977, 363-364).

Inicialmente Feyerabend aplica su noción de inconmensurabilidad para referirse a la incompatibilidad conceptual que existe entre enunciados o teorías científicas sucesivas $(1958 b, 163 ; 1962 / 1989,39)$. Esto ha dado lugar a que su doctrina de la inconmensurabilidad sea reducida a una inconsistencia semántica entre teorías rivales. Ejemplo de ello son los estudios que ofrecen sobre esta cuestión Sankey y Hoyningen-Huene (2001, ix-xiii), Devit (2001), Shapere (1966), y Preston (1997, 86-88, 102, 157, 184; 2000, 88-89).

En estos estudios se obvia que Feyerabend no se limita a aplicar su noción de inconmensurabilidad a los conceptos y a las teorías, sino que — tal como muestra Oberheim - la extiende también a la relación que puede existir entre cosmovisiones, tradiciones, culturas, comunidades, paradigmas valores, prácticas, acciones, percepciones, cuestiones, problemas, etc. (Oberheim, 2006, 130). Pero fundamentalmente estos críticos ignoran que el mismo Feyerabend niega explícitamente que su doctrina de la inconmensurabilidad sea de una naturaleza lingüística. En la introducción que precede al vol. I y II de los Philosophical Papers afirma que su tesis de la inconmensurabilidad no constituye ningún intento de esbozar las consecuencias de una teoría contextual del significado. Aún más subraya que las teorías del significado no juegan ningún rol en esta discusión (1981b), x; 1961/1995, 386; 1965/1981a, 97, 102-103; 1965/1981b, 113 
y 130) $)^{5}$. En Explanation, Reduction and Empiricism (1962) lejos de reducir la inconmensurabilidad a una inconsistencia semántica, postula que ésta última no es más que uno de los resultados o efectos de la inconmensurabilidad ontológica entre teorías:

«[...] lo que ocurre cuando se da el paso de una teoría $T^{\prime}$ restringida a una teoría T más amplia (capaz de abarcar todos los fenómenos abarcados por T') es algo mucho más radical que la incorporación de la teoría $T^{\prime}$ inalterada al contexto de T, que es más amplio. Es, más bien, una sustitución de la ontología de $\mathrm{T}^{\prime}$ por la ontología de $\mathrm{T}$, y el correspondiente cambio en el significado de todos los términos descriptivos de $\mathrm{T}^{\prime}$ (suponiendo que esos términos se sigan empleando)» (Feyerabend, 1962/1989, 92).

La sustitución de ontología es propiamente la causa del consiguiente cambio del significado de los términos teóricos y observacionales. La existencia de una inconsistencia semántica depende en definitiva de un cambio en la manera de entender y explicar el mundo. Este giro en su modo de comprender la naturaleza y causa de la relación de inconmensurabilidad entre teorías no instánciales, Feyerabend lo explica explícitamente:

"Yo creía desde hace algún tiempo que las diferencias conceptuales siempre serían acompañadas por diferencias perceptuales, pero abandoné esta idea en mi [1965a], el texto en las notas a pie de página 50 y sig. (la razón: la idea no está de acuerdo con los resultados de la investigación psicológica). En Contra Método, p. 238 y sig. advertí contra 'una inferencia del estilo (o la lengua) a la cosmología y al modo de percepción' y especifiqué condiciones en las cuales tal inferencia puede ser hecha» (Feyerabend, 1977, 365, n. 1).

En Adiós a la Razón (1987) Feyerabend explica que fue formulando su versión ontológica de la inconmensurabilidad en la medida que fue descubriendo la dependencia de los elementos metodológicos y semánticos con respecto a la ontología de la teoría:

"Anthony Perovich (AP) muestra que, al discutir la inconmensurabilidad, yo he pasado de una versión semántica a una versión ontológica, y que ocasionalmente he confundido ambas cosas. El cambio se explica (post hoc, jdesde luego!) por mi creciente convicción de que la metodología es algo parasitario en la ontología y no al revés. [...] Yo añadiría que los 'principios universales' no deben interpretarse de una forma demasiado intelectualista (TCM, página 264 y siguientes). Por ejemplo, no deben interpretarse como principio de uso

5 Evidentemente Feyerabend en numerosos artículos se ocupa de la cuestión de la interpretación del significado de los términos o sentencias (Cf. Feyerabend, 1955/1981, 99-130; 1958/1981a, 17-36; 1960/1981a, 37-43; 1962/1981a, 44-96; 1965. En (1958/1981a) presenta efectivamente la inconmensurabilidad como una consecuencia lógica de su teoría pragmática de la observación. No obstante, en la medida que Feyerabend descubre que las cuestiones semánticas y metodológicas son dependientes de los elementos ontológicos de las teorías, formula de una manera más precisa su versión ontológica de la inconmensurabilidad (FeYerabend, 1987/2005,54; 1978/1982, 254-255). 
lingüístico que pueden separarse de su empleo y discutir aisladamente» (Feyerabend, 1987/2005, 54).

Antony Perovich es quien tiene el mérito de haber expuesto en su artículo Incommensurability, its Varieties and its Ontological Consequences (1991) la naturaleza ontológica de la doctrina de la inconmensurabilidad de Feyerabend Allí demuestra que su formulación más madura de tal doctrina sitúa a la sustitución de ontología como la explicación última del cambio o variación del significado (Cf. Perovich, 1991, 317).

Por su parte, Gonzalo Munévar (2006, 40, 144-145; 2000, 73-74). prueba que el problema de la inconmensurabilidad en la obra del vienés es independiente de una teoría lingüística. Explica que ya sea que uno sostenga el operacionismo de Bridgman según el cual el significado de los términos científicos debe ser determinado por operaciones; o que nos inclinamos por la teoría de Hempel, según la cual el significado de un término depende en parte del rol que este juega dentro del marco de una teoría, el problema de la inconmensurabilidad permanece. Cuando cambiamos de una teoría a otra, también cambian evidentemente las 'operaciones' o instrumentos experimentales a través de las cuales definimos los términos. $\mathrm{O}$, en el caso de que optemos por la teoría de Hempel, advertimos que todo cambio de teoría nos conduce a un cambio de significado de sus términos. Los términos científicos no son convertibles de una teoría a otra: son inconmensurables. La intención de Feyerabend no es tomar postura por una teoría particular sobre el lenguaje sino mostrar, cómo la visión del mundo y de la realidad en la que se inscribe una teoría científica, afecta el uso y significado de sus términos.

La tesis que condujo a Feyerabend al problema de la inconmensurabilidad no fue una teoría lingüística sino el descubrimiento de la incidencia que tienen los elementos ontológicos o una tradición metafísica en el quehacer científico. Él mismo en La Ciencia en una Sociedad Libre (1978) presenta "la noción de inconmensurabilidad, [como una] consecuencia natural de la identificación de las teorías con las tradiciones» (Feyerabend, 1978/1982, 72). Ésta es la causa y raíz de la inconmensurabilidad. Y justamente aquí es donde el segundo Wittgenstein parece haberle ofrecido un significativo aporte (Feyerabend, 1978/1982, 73).

La tesis de la inconmensurabilidad ontológica es aquella que revela la relación de inconsistencia entre teorías comprensivas en cuanto que éstas están informadas por ontologías mutuamente excluyentes.

Feyerabend asegura que «una teoría es incompatible con otra si sus consecuencias ontológicas son incompatibles con las consecuencias ontológicas de la última» (Feyerabend, 1981b, xi). Lo que ocurre cuando se pasa de una teoría A a una teoría B -explica Feyerabend- «es una sustitución de la ontología» (Feyerabend, 1962/1989, 39), y un correspondiente cambio en el significado de los términos teóricos y observacionales (1962/1989, 39). Es decir, la inconmensurabilidad ontológica es en definitiva la causa y explicación última de la 
inconsistencia semántica y metodológica entre teorías. En La Ciencia en una Sociedad Libre (1978) escribe:

«Pero lo que yo digo no es que las pinturas sean inconmensurables entre sí, sino que las cosmologías que de ellas (y de la literatura, la filosofía, la teología e incluso la geografía de la época) se infieren son inconmensurables». (Feyerabend, 1978/1982, 254-255).

Dicho de otro modo, para Feyerabend la inconmensurabilidad aspectual o lingüística no son más que aspectos o partes constitutivas de la verdadera causa de la inconmensurabilidad. Para el vienés la irreductibilidad del contenido, la variación en el significado de los términos, las dificultades de traducción recíproca de sus términos, la incapacidad de determinar un referente común, la ausencia de una mutua inteligibilidad y de estándares comunes para evaluar distintas teorías comprensivas, etc. no son más que el resultado de la inconsistencia ontológica entre teorías no instánciales o comprehensivas. (Feyerabend, 1958a, 78-79, 90-91; 1958/1981a, 29 y 35; 1961/1999, 52-54; 1962/1981a, 323; 1962/1989, 77-78, 137-138; 1965/1981b, 109-110; 1967a, 40; 1975/1992, 102-103; 1977, 365, n. 1). En este sentido, la explicación que ofrece Feyerabend de la tesis de la inconmensurabilidad parece ser más radical y abarcante que la de Kuhn' ${ }^{6}$.

La inconmensurabilidad — según el vienés_- describe la relación de inconsistencia entre teorías universales o comprehensivas (Cf. Feyerabend, 1958a, 7879, 90-91; 1958/1981a, 29, 35; 1961/1999, 52-54; 1962/1981a, p. 323; 1962/1989, 137-138; 1965/1981b, 109-110; 1967a, 40; 1975/1992, 102-103; 1977, 365, n. 1; 1977/1999, 204) ${ }^{7}$, es decir, entre aquellas que tienen implicancias ontológicas distintas. La inconmensurabilidad describe la relación entre aquellas teorías que son lo suficientemente ricas como para dar una explicación acerca de la naturaleza de todos los fenómenos físicos (Feyerabend, 1962/1989, 137-138) y que son capaces de sustituir a las demás cosmovisiones como un todo (Feyerabend, 1962/1989, 38), tales como la teoría aristotélica, la teoría Newtoniana, o la teoría cuántica (Feyerabend, 1958/1981a, 29, 35). En pocas palabas, fue el esclarecimiento del papel imprescindible que juega la metafísica y/u ontología en las teorías científicas no instánciales, lo que condujo a Feyerabend al problema de la inconmensurabilidad. La doctrina de la inconmensurabilidad es la cuestión sobre el cual Feyerabend amplia la noción de ciencia. A través de ella —como se expone en el siguiente punto- descubre que aquellos elementos que pretendían excluir tanto el positivismo lógico como el racionalismo crítico

6 Para una exposición de las características que comparten la concepción de Kuhn y Feyerabend acerca de la relación de inconmensurabilidad entre teorías se puede ver Hoyningen-Huene 2000b, 104-105. Para estudiar, en cambio, las diferencias que existen entre ambas se puede ver OвERHEIm, 2006, 125-127.

7 Esta restricción de la tesis de la inconmensurabilidad a las teorías comprehensivas constituye para Hoyningen-Huene la diferencia principal entre la concepción de inconmensurabilidad de Feyerabend y la de Kuhn. (Cf. Hoyningen-Huene, 2000b, 106). 
de Popper a un contexto de descubrimiento, o a un ámbito pre-científico o preracional constituyen el corazón de la misma ciencia.

Entre el 55 y 68 Feyerabend utiliza frecuentemente la noción de 'metafísica' en el sentido popperiano, es decir, para referirse a todo aquello que no puede ser objeto de falsación empírica (Cf. Feyerabend, 1960/1981a, pp. 42-43). En este sentido, una teoría será metafísica en la medida que no sea posible especificar un resultado experimental que pueda ponerla en peligro u obligarnos a abandonarla. Feyerabend asume esta concepción de la metafísica no como una tesis propia sino en orden a llevar cabo una reducción al absurdo de la misma, es decir, con el fin de mostrar la contradicción intrínseca que supone.

Además de esta referencia a la concepción popperiana de metafísica, el epistemólogo con la noción de metafísica se refiere, en un marco más general, a todos aquellos elementos que no son susceptibles de comprobación empírica y en este sentido coincide con lo que el positivismo lógico en general entiende por metafísica (Cf. Feyerabend (1962/1989), pp. 17 y 40; (1970/1989), p. 140141). La metafísica es caracterizada dialécticamente por el positivismo como lo no científico, extendiéndose así a todo juicio de valor, prejuicio o concepción ontológica, estética, moral, política o religiosa. Pues bien, cuando Feyerabend utiliza esta noción ambigua e imprecisa de metafísica le interesa demostrar la paradoja por la cual todos aquellos elementos que el positivismo lógico considera como carentes de sentido - pues no pueden ser criticados y desarrollados según sus 'cánones de racionalidad' - constituyen la materia que fecunda la tarea científica.

Pero en otros pasajes Feyerabend prefiere hablar no ya de metafísica sino de ontología, para referirse a las visiones del mundo que informan la actividad científica. Reconoce como ontológico a todo sistema conceptual comprehensivo lo suficientemente rico como para esbozar una explicación de la totalidad de las apariencias físicas y, por tanto, capaz de sustituir a las demás cosmovisiones como un todo (Cf. Feyerabend, 1958a, 78-79, 90-91; 1961/1999, 52-54; 1962/1981a, 323; 1962/1989, 38, 77-78, 137-138; 1965/1981b, 109-110; 1967a, 40; 1975/1992, 102-103; 1977, 365, n. 1).

Feyerabend (1963/1999, 87-88) asegura que entiende la ontología en el mismo sentido que Quine, es decir, como visiones contingentes o eventuales que facilitan descripciones hipotéticas acerca de la estructura y naturaleza del mundo físico. Feyerabend asume la concepción de ontología de Quine (1986; 1992) como aquella ciencia relativa a la elección de una eventual red lingüística dentro de la cual reificamos el material observacional. Pero la asume en orden a reducir al absurdo la pretensión de que la ontología se limite a preguntarse por la existencia de entidades dentro de un discurso lingüístico. En sus numerosos artículos en torno a la mecánica cuántica denuncia insistentemente la necesidad de que la mecánica cuántica posea una autentica referencia ontológica y no únicamente un marco ontológico que explique el comportamiento cuántico de acuerdo a sus propios principios (Cf. Feyerabend, 1958, 80; 1962/1981, 312-3; 1966, 416-417). 


\section{LAS CONSECUENCIAS DE LA INCONMENSURABILIDAD}

Entre las controversias y discusiones suscitadas en torno a la doctrina de la inconmensurabilidad no se aprecia una comprensión cabal del sentido y las implicancias que ésta tiene para Feyerabend. Los críticos y especialistas en el vienés se limitan a presentar el problema de la inconmensurabilidad como si ella condujera única y necesariamente a concepciones relativistas, escépticas o instrumentalistas respecto la ciencia sin comprender la intencionalidad última de Feyerabend. Sugieren que su doctrina de la inconmensurabilidad promueve una visión escéptica, fragmentaria, irracional y relativista respecto a la ciencia en cuanto que impide toda posibilidad de explicar el progreso, la objetividad o el realismo científico (Cf. Preston, 1997, 5-6; 2000, 94; Lloyd 2000, 115; Gellner, 1975, 336; Watkins, 2000, 49; Ribes, 1989, 15-16; Giedymin, 1971; Grunfeld 1984; Theocharis and Mihalis, 1987, 598; Bunge, 2003, 30; Horgan, 1993, 36; Nickels, 1998; Rossi, 1975, 266; Finocchiaro, 1973, 361; Bhaskar, 1975, 39, 4546; Andersson, 1984, 13-23; Counihan 1976, 470-472; Kulka, 1977, 277-282; Hattiangadi, 1977, 289; Broad, 1979, 537; Worrall 1978b, 279-280.

Pues bien, atendiendo a los sentidos con los que Feyerabend aplica la noción de metafísica y ontología y comprendiendo la naturaleza ontológica de su doctrina de la inconmensurabilidad podemos pasar a dilucidar la intencionalidad y el objeto de su denuncia.

La tesis de la inconmensurabilidad significó una verdadera revolución en el campo de la filosofía de la ciencia. La inconmensurabilidad constituye para Feyerabend un cuestionamiento a un modo particular de concebir la racionalidad científica y a sus consecuentes nociones de objetividad, progreso y realismo científico. El alcance de esta tesis lo presenta explícitamente en su Tratado contra el Método (1975):

«La inconmensurabilidad, que examino más adelante, está estrechamente relacionada con la cuestión de la racionalidad de la ciencia. En realidad, una de las objeciones más generales, no sólo contra el uso de teorías inconmensurables sino incluso contra la idea de que existan tales teorías en la historia de la ciencia, es el miedo de que restringirían severamente la eficacia de la argumentación tradicional no dialéctica. Examinemos, pues, con un poco más de detalle los standards críticos que, según algunos, constituyen el contenido de una argumentación ,racional'. Más en particular, examinemos los standards de la escuela popperiana cuya ratiomanía nos concierne principalmente» (Feyerabend, 1975/1992, 157).

Pero Feyerabend no pretende - tal como sugiere la literatura recién mencionada - postular positivamente el relativismo, la irracionalidad o el escepticismo respecto a la ciencia. Insiste que no se puede hacer responsable a la doctrina de la inconmensurabilidad de estas valoraciones de la ciencia:

«Bueno, [con la doctrina de la inconmensurabilidad] no me proponía realizar, desde luego, una contribución de carácter positivo. Sólo quería criticar una tesis popular, pero en mi opinión, susceptible de inducir a error, sobre la 
explicación y la reducción. Para criticar esta tesis, he señalado una característica del cambio científico que la tesis en cuestión no podía explicar, y la he llamado «irreductibilidad». Por lo que a mí respecta, la irreductibilidad no representa una dificultad para la ciencia ni, a este respecto, para nadie — sólo representa una dificultad para algunas doctrinas filosóficas muy ingenuas y, como se considera que estas doctrinas son ingredientes esenciales de un cierto tipo de «racionalidad», también para las concepciones de esta clase. [...] El fenómeno que he denominado irreductibilidad sólo da razón de una pequeña parte de estos equívocos, y considero no sólo ingenuo, sino verdaderamente criminal, convertirlo en un gran Monstruo, responsable de todos los males de la ciencia y del mundo en general» (Feyerabend, 1989/2000, 158).

Por el contrario, lo que pretende mostrar, por reducción al absurdo, es que estas actitudes no son sino una consecuencia lógica que se sigue de los mismos supuestos del positivismo lógico y del racionalismo crítico:

«(Otra conclusión es que los racionalistas no han logrado todavía derrotar el escepticismo: todos los puntos de vista son igualmente buenos o, dicho de otra forma — que no es más que su natural prolongación-, toda valoración de las teorías y formas de vida es aceptable).

[...] A este seudorazonamiento se le puede desenmascarar por medio del análisis académico o se le puede reducir al absurdo. Yo elegí este último camino» (Feyerabend, 1978/1982, 173-174) $)^{8}$.

La inconmensurabilidad es una reducción al absurdo de los intentos del racionalismo crítico y del positivismo lógico por definir la ciencia. Denuncia el fracaso de tales tradiciones para dar cuenta de la racionalidad científica, y particularmente de nociones tales como progreso científico y objetividad científica. Pasemos a considerar, a continuación, como ella objeta la noción de progreso científico.

\subsection{La inconmensurabilidad y el progreso científico}

La inconmensurabilidad cuestiona directamente la posibilidad de hablar de progreso científico en los términos del Popper o del positivismo lógico. Éstos definen el progreso de la ciencia en virtud del aumento de contenido empírico. Una teoría tiene contenido empírico solo si ésta es comprobable o falseable - afirma el vienés $(1961 \mathrm{a}, 402)$ tratando de abarcar con tal definición tanto la visión de Popper $(1980,120)$ como la de Carnap (1978, 67 y 85) al respecto-.

Popper distingue dos tipos de sentencias básicas lógicamente posibles:

«[...] la clase de todas aquellas sentencias básicas con las cuales algo es inconsistente (o que éstas excluyen, o prohíben): llamamos a esto la clase de falseadores potenciales de la teoría; y en segundo lugar, la clase de todas

8 Entre los pasajes donde Feyerabend presenta el relativismo como una consecuencia lógica del racionalismo se pueden mencionar los siguientes (FEYERABEND, 1978/1982, 141-142, 173-174; 1976, 385-388; 1981e, 21-22; 1987b, 19-20; 1989, 395 n. 4, 399-400; 1991a, 89-90, 101; 1992, 367-368; 1993/2008, xiii-xiv). 
aquellas sentencias básicas con las cuales algo no se contradice (o que éstas 'permiten')»(Popper, 1980, 86. Mi traducción).

Para Popper $(1980,120)$ aquellas sentencias que establecen falseadores potenciales de una teoría constituyen el contenido empírico de una teoría. Es necesario destacar que Popper no concede a las sentencias básicas un carácter fundacional o indubitable. Por el contrario, en Conjeturas y Refutaciones (1972, 388) sostiene que todos los términos son teóricos, aunque algunos son más teóricos que otros. Esto implica que las sentencias observacionales que componen la base empírica son teóricas, singulares, relativas a hechos observables y, por ende, objetos de falsaciones intersubjetivas (Cf. Popper, 1980, 44, 102-103) 9 .

Feyerabend asume esta concepción y el principio de aumento de contenido según el cual una teoría es preferible en cuanto ofrece mayor información que las teorías precedentes. Pero no lo hace en orden a defender positivamente esta concepción o principio ${ }^{10}$, o para proponer una nueva visión como sugiere Preston (1997, 133-134), Ronald Laymon $(1977,229)$ y Nélida Gentile $(2007,101)^{11}$. El vienés asume el ideal del aumento de contenido empírico, pero no porque esté comprometido con él, sino en orden llevar a cabo una crítica inmanente al positivismo y al racionalismo. Lo que pretende demostrar es la impotencia de tal definición para dar cuenta del progreso científico en la sucesión de teorías comprehensivas mutuamente inconmensurables.

9 Es pertinente esta precisión ante la confusión de Laudan (1996, 107-108) y Worrall (1978a, 303-304) quienes acusan a Feyerabend de incoherente debido a una errónea comprensión que ellos mismos poseen acerca de lo que es para Popper el contenido empírico. Ambos cuestionan a Feyerabend si toda teoría va a ser inconsistente con una teoría por el solo hecho de considerar consecuencias empíricas contrarias. Uno y otro entienden el contenido empírico o los falseadores potenciales como la negación de las consecuencias empíricas de una teoría. Pero tal definición es falsa. Para Popper aquellas sentencias que niegan el contenido empírico de una teoría no constituyen en sí mismas falseadores potenciales. Para ello, es necesario además que las sentencias básicas cumplan los requisitos que se explicitan arriba.

10 De hecho, Feyerabend insiste reiteradamente que, en la ciencia, así como en el arte, no existe propiamente progreso. O siendo quizás más precisos, afirma que desde las categorías del racionalismo crítico y del positivismo lógico no se puede hablar propiamente de progreso científico. Éstos deben reconocer que solo hay cambios o una sucesión de teorías, tradiciones o paradigmas mutuamente inconmensurables. (Cf. FeYerabend, 1958/1981a, 29 y ss.; 1958a, 81-83; 1958/1981b, 240, n. 6; 1960/1981b, 219; 1961b, 246-247; 1961/1999, 70; 1962/1981b, 83 y $88 ; 1962 ; 1963 / 1999), 83$ y ss.; 1965, 170 y 199; 1965/1981b, 107 y 110; 1967b, 117.

11 John Preston y Ronald Laymon acusan paradójicamente a Feyerabend de positivista en cuanto que el único criterio que ofrece para elegir entre teorías alternativas es el aumento de contenido empírico, ideal propio del positivismo lógico. Nélida Gentile formula un razonamiento análogo argumentando que los ideales del positivismo parecen animar tanto el realismo conjetural como el pluralismo metodológico de Feyerabend. Probablemente la confusión de Preston, Laymon y Gentile se debe a desconocer uno de los recursos habituales que emplea Feyerabend para mostrar la inconsistencia de la tesis que ataca, es decir, su uso de los razonamientos por reducción al absurdo. 
La inconmensurabilidad cuestiona la capacidad del positivismo lógico y del racionalismo crítico de dar cuenta del progreso científico en un cierto tipo de transición teórica. Pues mientras éstos definen el progreso como el proceso en el cual las teorías existentes son mejoradas o el número de hechos conocidos es simplemente incrementado; la inconmensurabilidad prueba que los principales avances teóricos no son parte de un proceso continuo de aumento de contenido o de enriquecimiento de ideas ya establecidas sino que obligan a una revisión del estatus ontológico de las antiguas teorías (Cf. Feyerabend, 1962, 198; 1965, 88-89, 176; 1965/1981b, 111; 1970/1989, 117-118; 1978/1982, 200, n. $38 ; 1992,367-368)$.

La inconmensurabilidad supone la existencia de un cambio conceptual radical. Según ella los términos de una nueva teoría no se refieren a ninguna de las entidades designadas por las teorías anteriores. Esta variación o discontinuidad de referente invalida la noción de progreso. Pues si las teorías no pueden ser comparadas con respecto a un contenido o referente común entonces es imposible evaluar el progreso científico. Si no existe posibilidad ni patrón común que permite comparar una teoría con otra ¿en función de qué se puede determinar que una teoría es mejor o más verdadera que otra?

La argumentación es análoga aun cuando se expone el problema de la inconmensurabilidad bajo la forma de una intraducibilidad del lenguaje de una teoría a otra, o bajo la forma de la ininteligibilidad recíproca entre los esquemas conceptuales de dos teorías rivales ${ }^{12}$. La variación semántica de los términos impide que los contenidos de las teorías puedan ser directamente comparados y embarga la posibilidad de acceder desde uno u otro a una recíproca intelección. Cada teoría propone términos para entender la experiencia con un sentido muy distinto al de los términos propuestos por las otras teorías. Pues bien, si las teorías no tienen un vocabulario común, el contenido de tales teorías no puede ser directamente comparado objetan los críticos (Cf. Sankey, Hoyningen-Huene, 2001, ix-xiii; Devitt 2001; Klimovsky, 2001, 382; Shapere,

12 Kuhn y Feyerabend distinguieron entre la intraducibilidad de lenguajes mutuamente inconmensurables y la posibilidad de acceder desde uno u otro a una reciproca comprensión. Ambos consideran que la traducción de un lenguaje, o de algunos de sus términos específicos, a otro lenguaje podría fracasar. No obstante, de esta intraducibilidad no se sigue necesariamente la imposibilidad de entender por inmersión un lenguaje que se nos presenta en principio como inconmensurable (Cf. KunN, 1983, 669-688; Feyerabend, 1975/1992, 265 266; 1987a, 75-81). La crítica provocada por estas dificultades ha planteado algunas soluciones alternativas: Donald Davidson, por ejemplo, asegura que es posible acceder a un lenguaje independiente que permite traducir teorías inconmensurables en la medida que se distinga entre un esquema conceptual y el contenido que es organizado por el esquema conceptual. (Cf. Davidson, 1984, 183-198). Howard Sankey adopta una versión modificada de la teoría de la referencia que permite un cambio en la referencia y concede un rol a la descripción en la determinación de la referencia. En el capítulo seis de su libro sobre inconmensurabilidad argumenta que podría haber un fracaso en la traducción de teorías debido a la diferencia de significado de la referencia. Pero este fracaso en la traducción se restringe únicamente a la descripción del referente. A pesar de la inhabilidad que puede existir para traducir teorías inconmensurables postula en ella referentes superpuestos o coincidentes (Cf. SANKEY, 1994). 
1966, 51). Ahora bien, si no hay un vocabulario semánticamente neutro —agrega Achinstein - es imposible saber si lo que una teoría niega o afirma acerca del mundo contradice o no las afirmaciones hechas por otra teoría. Cada una de las teorías hablaría de sí misma, de cosas acerca de las cuales ninguna otra teoría podría decir algo en absoluto, dejando así sin validez ni sentido el mismo concepto de contradicción y progreso científico (Cf. Achinstein, 1968, 93) ${ }^{13}$.

En general, sus críticos no supieron ver que la visión relativista de la ciencia que se seguía de la doctrina de la inconmensurabilidad no implica para Feyerabend el fracaso de la racionalidad científica en cuanto tal. Con ella busca cuestionar un determinado modelo de racionalidad con su consecuente noción de progreso científico. El vienés no pretende postula una concepción relativista respecto a la ciencia sino mostrar que el modelo positivista y racionalista de racionalidad debe reconocer el relativismo como una consecuencia que se sigue de su impotencia para poder explicar el progreso científico en ciertas transiciones teóricas.

Podríamos resumir el planteo de nuestro filósofo de la ciencia del siguiente modo: la transición de dos teorías comprehensivas mutuamente inconmensurables no puede ser explicada según los cánones y principios del positivismo lógico y del racionalismo crítico. Pues de hacerlo se encuentra ante la siguiente disyuntiva: o deben admitir el fracaso de sus principios para dar cuenta del progreso científico o deben proclamar un relativismo. Feyerabend opto por mostrar el absurdo de estas tradiciones por este segundo camino: a saber, exponer su fracaso mostrando una concepción relativista del progreso científico cuando es analizada desde sus propios principios.

\subsection{La inconmensurabilidad y el realismo científico}

La inconmensurabilidad ontológica atenta directamente contra el realismo científico. El realismo concibe la sucesión de teorías como descripciones alternativas de un dominio común de entidades que existen independientemente de pensamiento humano y de las teorías científicas. Ahora bien, la inconmensurabilidad ontológica cuestiona justamente la continuidad de la referencia ontológica en las teorías científicas rivales. ¿Cuál de las teorías alternativas trata con lo real? ¿Qué conceptos de las teorías en competencia describen algo de lo real y cuáles no? ¿Las teorías ontológicamente inconmensurables hablan o no hablan acerca de lo mismo? ¿Las ontologías de las teorías científicas son vías de acceso a la realidad o simplemente ofrecen la posibilidad de construir una infinidad de mundos alternativos? ¿Qué estatuto ontológico poseen las entidades

13 Feyerabend en respuesta a un comentario de Dudley Shapere admite que las sentencias que carecen de un significado común son incapaces de contradecirse reciprocamente (Cf. Feyerabend, 1965/1981b, 115. Pues - tal como explica Dilworth- solo son contradictórias aquellas teorías donde una teoría niega lo que simultáneamente afirma la otra. En la inconmensurabilidad hay únicamente una incompatibilidad en el orden de las cualidades que se le atribuyen simultáneamente a un mismo objeto (Cf. DiLworth, 2007, 59-62). 
que se constituyen en objeto de estudio de las teorías científicas? (Cf. Kordig, 1970, 400-401; Munévar, 1999, 221-222 ${ }^{14}$.

Antes estos interrogantes podrían parecer que Feyerabend mantiene en principio una postura ambigua, o al menos oscilante. Entre 1961 y 1970 asegura que los conceptos inconmensurables se refieren a un mismo núcleo de cosas. (Feyerabend, 1961/1995, 364; 1970/1981b, 156-159; Feyerabend y Hanson 1970, 247). Pero desde 1975 postula la tesis inversa: las teorías son construcciones con su propio dominio de referencia (Cf. Feyerabend, 1975/1992, 269-271; 1978/1982, 70).

Esta oscilación de Feyerabend respecto a la cuestión si entre dos teorías inconmensurables hay o no hay superposiciones referenciales constituye uno de los blancos de sus críticos ${ }^{15}$. Robert Farrell explica que no hay propiamente una oscilación por parte de Feyerabend; con estos cambios de parecer lo que quiere mostrar es la irrelevancia del problema acerca de la referencia (Farrell, 2003, 92-93).

14 Estos cuestionamientos han dado lugar a una variada literatura que ensaya distintas soluciones. Israel Scheffler (1967) asume la distinción de Fregue entre la referencia y el sentido. Asegura que aun cuando el sentido de los términos varíe en las transiciones teóricas, no se sigue una modificación en la referencia de dichos términos. Esta referencia común es lo que permite comparar el contenido de las teorías. Las distintas sentencias de las teorías podrían acordar o discordar con un estado común de cosas, podrían referirse a las mismas cosas, a pesar de la variación de su sentido. Pero Scheffler no cierra la cuestión. No explica los numerosos casos de la historia de la ciencia — de los que han dado cuenta tanto Kuhn como Feyerabend- en los que distintas teorías parecen emplear los mismos términos para referirse a cosas diferentes.

Saul Kripke y Hillary Putnam, por su parte, intentan superar el problema de incomparabilidad de teorías asegurando que el referente de los términos es independiente del contenido descriptivo o conceptual de las teorías. El referente es determinado de una manera directa por la relación causal entre el interlocutor y el objeto. Ahora, si la referencia de los términos permanece estable a través de la variación del contenido conceptual, entonces no existirá el problema de la comparación teórica (Cf. KRIPKE, 1980; Putnam, 1975).

La postura de Kripke y Putnam obtuvo como respuesta la objeción de Fine quien les mostró que en ella están excluyendo como un principio a priori la posibilidad de un cambio de referente. Ambos están excluyendo un hecho que es puesto de manifiesto en numerosos casos de la historia de la ciencia. Cf. FInE (1975). Este mismo argumento es formulado por Enç, Kroon y Nola quienes afirman que, si la referencia de los términos teóricos es determinada mediante la especificación de una relación causal entre los fenómenos observados y las entidades responsables de esos fenómenos, sería imposible que los términos teóricos fracasen en su referencia. No obstante - aseguran- vemos que en la historia de la ciencia este fracaso es una rutina. (Cf. Enç, 1976; Kroon, 1985; Nola, 1980). Por otra parte, Papineau, Devitt y Sterelny señalaron a Kripke y Putnam que, si el referente de los términos no está determinado por ningún significado descriptivo sino únicamente por la ostentación de los objetos, sería imposible asegurar una referencia inequívoca (Cf. PapinEau 1979; DevitT, STERELNY, 1999).

15 Los críticos apuntan que aquellas teorías que poseen una referencia común no se pueden decir recíprocamente inconmensurables (Cf. SCHEFfler, 1967; Putnam, 1965; 1975, 117-131; Kitcher, 1978; Parsons 1975; Devitt 1979; Sankey 1994). 
Feyerabend no sostuvo dos posturas contrarias - como parece dar a entender Craig Dilworth (2007, 78-79) — sino que, más bien, alcanza en 1975 una formulación más precisa del problema. En La Ciencia en una Sociedad Libre (1978) el vienés subraya que desde los cánones del positivismo lógico y del racionalismo crítico no hay modo de poder determinar desde el interior de una teoría científica si ella se refiere o no a la misma entidad que su teoría rival (Feyerabend, 1970/1989, 117-118; 1978/1982, 200-203, n. 38).

Esta formulación de la doctrina de la inconmensurabilidad no supone por parte de Feyerabend la defensa de una metafísica idealista. La inconmensurabilidad ontológica no es un pseudo-problema fruto de una metafísica neokantiana - tal como da a entender Devitt, Preston, Sankey y Hoynigen-Huene en el caso de Thomas Kuhn-. (Cf. Devitt, 2001; Preston, 1997, 100; HoynigenHuene 1993, Sankey, Hoyningen-Huene 2001, xvi). Feyerabend presenta la inconmensurabilidad como un hecho histórico, y no como el resultado de una metafísica idealista. La misma historia de la ciencia pone de manifiesto cómo en ciertas transiciones teóricas existe una sucesión de supuestos ontológicos que son recíprocamente inconsistentes (Cf. Feyerabend, 1981b, x y xv; 1981a, cap. 2.4 , cap. 15 , cap. 16 y cap. 17; 1962/1989, 93-94; 1975/1992, 282-283).

En su teoría pragmática de la observación Feyerabend supone la existencia independiente de un mundo que es fuente de las percepciones ${ }^{16}$. Concibe las sentencias observacionales como aquellas sentencias con las que el observador imita los estímulos perceptuales. Las teorías no son sino intentos de describir realísticamente la naturaleza de este mundo (Cf. Feyerabend, 1958/1981a). En este sentido, su realismo normativo implica reconocer que todas las teorías tienen una referencia común. Las descripciones acerca de la naturaleza de las entidades y los procesos constitutivos del mundo difieren radicalmente de una teoría a otra. No obstante todas ellas se refieren a un único mundo ${ }^{17}$.

Ahora bien, si se interpreta a Feyerabend desde una metafísica idealista y desde ella se analizan aquellos pasajes donde afirma que las entidades están constituidas por las teorías (Cf. Feyerabend, 1960/2005, 299-300; 1962/1981, 45 ; 1962/1989, 40, 136-137; 1963, 321-323; 1970/1989, 106-107; 1970/1999b, 129-131; 1977, 353; 1978/1982, 199-203; 1987/2005, 44-46), se puede afirmar

16 Feyerabend dice asumir la teoría pragmática de la observación de Popper, Carnap y Neurath quienes supieron defenderla a lo largo de la década del 30 para finalmente abandonarla. El positivismo lógico original suscribía que las sentencias observacionales eran relativas a los datos sensibles y, por ende, a observaciones. Popper, Carnap y Neurath contra esta visión argumentan que las sentencias observacionales son relativas a objetos físicos externos y no a eventos psíquicos internos. Feyerabend asume esta última visión sosteniendo que las observaciones son causadas por objetos físicos y que las sentencias observacionales son refieren a éstos y no a meros eventos psicológicos (Cf. FEYERABEnd, 1958/1981a, 17-36; 1962/1981b, 49 y ss.; 1965, 152, 198-199, 240 y ss.; 1965/1981b, 125).

17 Feyerabend (1960/1981b: 224; 1966: 4) reconoce tanto a Popper como a Kraft como las fuentes de su realismo normativo. OBERHeIm $(2006,191)$ precisa aún más esta incidencia de estos filósofos, indicando que Feyerabend adapta el realismo normativo de Kraft al realismo conjetural de Popper. 
coherentemente — tal como lo hace Sankey (1994, 147)— que las teorías inconmensurables no poseen un referente común. Pues una metafísica idealista conduce lógicamente a postular una radical discontinuidad referencial entre teorías inconmensurables.

Feyerabend reconoce efectivamente que el significado y la referencia están íntimamente conectados. En Reply to Criticism. Comments on Smart, Sellars and Putnam (1965), escribe que «las conversaciones acerca del significado pueden ser remplazadas, sin desperdicio, por las conversaciones acerca de las teorías» (Feyerabend, 1965/1981b, 114, n. 27). No obstante, nunca sostuvo que estas realidades sean intercambiables. Asegura que la referencia está determinada por el contenido de las teorías y que las percepciones que provienen del mundo son descriptas por las teorías. Sin las teorías las entidades o procesos no existirían tal como son pensadas, interpretadas o descriptas por las teorías. (Cf. Feyerabend, 1958a; 1958/1981a, 32-33; 1959, 82; 1960/1981a, 37-43; 1960/1999; 1960/2005; 1962/1981b, 45-46; 1965, 198 y 219-224 n. 8; 1969/1981a, 132-135).

En numerosos pasajes de su obra Feyerabend aboga por un realismo normativo en contraposición con el instrumentalismo (Cf. Feyerabend, 1954/1955, 462-465, 473-477; 1958/1981a, 17-36; 1958a, 75-104; 1958c, 343; 1960/1981a, 37-43; 1961/1999, 50-77; 1964/1981, 176-202; 1966, 5-6; 1968, p. 321; 1975/1992, 185; 1978/1981, 87-88; 1980/1981, 90-91; 1981f, 218, 224-225; 1993/2008, 132140) y el realismo ingenuo (Feyerabend 1958a, 78-81; 1991b, 118; 1991/2003, 25-26, 54-58, 165 y ss.; 1994/2000, 117-118, 135-136, 139-141, 154-156 y ss.; $1999,91-92)$. Mientras que éste último considera lo real como algo dado, él postula que lo real se comprende en función de lo teórico. En la introducción del volumen I y II de sus Philosophical Papers, Feyerabend, aludiendo al realismo implícito en sus primeros artículos afirma que «El realismo nos invita a rechazar el sentido común y a anunciar este descubrimiento: se ha encontrado que la realidad objetiva es un error metafísico» (Feyerabend, 1981d, xii). Según el vienés, conocemos la realidad en función de nuestros conceptos, comprendemos el objeto real en función del objeto teórico. Pero esto no implica, en absoluto que haya identificado el objeto real con el objeto teórico.

«Por lo demás, nunca he afirmado la identidad de lo que es y de lo que se piensa que es ('confusión' de objetos teóricos y objetos reales). El 'realismo', tal y como se define en el capítulo de la inconmensurabilidad, no implica la identificación de lo real con el objeto teórico; "realismo» quiere decir que se trata de comprender lo real en función de lo teórico en lugar de considerarlo como algo «dado». Al menos éste es mi punto de vista sobre la relación entre el objeto real, el objeto teórico y el objeto de la experiencia» (Feyerabend, 1978/1982, 201, n. 38).

En su doctrina de la inconmensurabilidad Feyerabend quiso mostrar contra el positivismo lógico y al racionalismo crítico, las dificultades que éstos encuentran en ciertas transiciones teóricas para determinar lo real, lo objetivo, lo racional cuando entra en escena una nueva concepción del mundo (Cf. Feyerabend, 1962/1981b, 73-74; 1977, 367; 1987/2005, 181-18). Afirma que «En tales 
situaciones no puede ser realmente esbozada una distinción entre los fenómenos y la interpretación por un lado y los fenómenos y hechos objetivos por el otro" (Feyerabend, 1958/1981a, 28).

Demuestra que es imposible poder distinguir desde el interior de una teoría científica el objeto real del objeto teórico, los elementos subjetivos de los objetivos, lo metafísico de lo empírico, lo racional de lo que parece ser irracional (Cf. Feyerabend, 1991a, 101-102). Pues cada teoría científica, en función de la ontología o visión del mundo que la anima, establece un criterio de demarcación particular y arbitrario entre estas realidades. De aquí que los participantes de una teoría se ven obligados a reconocer en una revolución científica que no pueden dominar, con las formas de racionalidad que tienen a su alcance, la nueva ontología o visión del mundo que supone la nueva teoría.

Desde el exterior de una teoría su puede fácilmente racionalizar cualquier transición teórica -asegura Feyerabend contra Lákatos-. Pero tampoco en este caso se encuentra un criterio epistémico externo a las teorías inconmensurables que nos permita definir qué es lo real, qué es lo progresivo o qué es lo racional (Feyerabend, 1977, 364, n. 2; 1978/1982, 188; 1987/2005, 88-89). Esto es lo que lo conduce a Feyerabend a presentar como una consecuencia lógica un relativismo según el cual las teorías científicas no son más que descripciones arbitrarias, todas ellas igualmente válidas o equivalentes (Feyerabend, 1976, 385-388; 1978/1982, 141-142, 173-174; 1981e, 21-22; 1987b, 19-20; 1989, 395 n. 4, 399-400; 1991a, 89-90, 101; 1992, 367-368; 1993/2008, xiii-xiv) ${ }^{18}$.

Uno de los textos donde Feyerabend sintetiza la intencionalidad última de su doctrina de la inconmensurabilidad, es decir, donde expone lo que pretende cuestionar con ella, lo encontramos en el siguiente párrafo de La Ciencia en una Sociedad Libre (1978):

«Ahora bien, cuando me ocupe de la inconmensurabilidad no sólo pretendía hacerle la vida imposible a los racionalistas críticos, sino también comprender los cambios que sobrevienen al entrar en escena una nueva concepción del mundo. Estos cambios pueden ser analizados de muchas formas. Pueden ser analizados 'desde el exterior', esto es, contemplándolos desde la perspectiva de una filosofía privilegiada (el marxismo, en el caso de CS). No niego que esta clase de análisis sea posible ni tampoco que pueda lograr racionalizar cualquier cambio (CS me atribuyen la creencia en la «imposibilidad de racionalizar todo cambio científico» [p. 331], pero lo cierto es que yo restrinjo la inconmensurabilidad a tipos especiales de cambio y admito que los 'enfoques externos' pueden llegar a racionalizar incluso estos cambios especiales [TCM, p. 224]). Sin embargo, lo cierto es que un análisis desde el exterior no me interesa demasiado. Lo que me interesa no es como se ve un hecho concreto cuando se proyecta sobre otra ideología, sino cómo se le ve 'desde el interior' (es decir, como le ven las partes implicadas). ¿Pueden estas

18 Para una visión crítica se puede ver Dilworth, 2007, 53; Russell, 1983, 440-443; Gellner, 1975, 336; Munervar, 2000a, vi; 2006, 76-77; Van FraAssen, 2000, 32; Preston, 1997, 121-122, 174-175, 177-179, 191-193; 2000, 91-92; Lloyd, 2000, 119-120; HatTiangadi, 2000, 141-142; OBerheim, 2006, 102-103; FarRell, 2003, 102 y 147. 
partes conferir sentido a los cambios acontecidos? ¿Puede someterlos a los que consideran que es su propia racionalidad o se ven obligados a reconocer que forman parte de un proceso que no pueden dominar con las formas de razón que tienen a su alcance? Esta es, dicho sea de paso, la pregunta que se suscita cada vez que se da una revolución científica. La pregunta no es, pues, si el científico en su conjunto parecerá razonable quinientos años después, sino hasta qué punto se le puede hacer razonable en su momento, hasta qué punto se debe permitir una violación de la razón ('razón' significa siempre la forma de razón que está al alcance de los participantes). Evidentemente, este análisis es de la máxima importancia para cada investigador, puesto que le prepara para acontecimientos que de otro modo podrían pillarle por sorpresa» (Feyerabend, 1978/1982, 202, n. 38)

La inconmensurabilidad en cuanto descubre lo metafísico en el seno de la actividad científica pone en crisis un modelo de ciencia que es heredero de una tradición epistemológica que intenta definir lo científico a expensas de lo metafísico (Cf. Feyerabend, 1970/1989, 89-90; 1975/1992, 167, 203-205; 1991a, 137-138). La epistemología moderna, y luego la filosofía de la ciencia, en sus intentos de fundar o definir la objetividad o la racionalidad del conocimiento científico ideo todo tipo de distinciones. A saber, la distinción de Hume entre cuestiones de hecho y relaciones entre ideas (Cf. Hume, 2004); distinción que fue retomada más tarde por Kant en su división entre juicios sintéticos y juicios analíticos (Cf. Kant, 2003), y posteriormente por el positivismo lógico para el cual la distinción analítico-sintético se convertirá en la piedra angular de la teoría empirista del significado (Cf. Hahn, Neurath y Carnap, 2002). A esto se suma la distinción entre teoría y método que caracteriza al racionalismo científico.

Para Feyerabend la inconmensurabilidad implica una crisis de esta tradición epistemológica que busca dar cuenta de la objetividad, la racionalidad y el progreso científico en los términos de dichas distinciones.

«Los resultados hasta aquí obtenidos aconsejan abolir la distinción entre un contexto de descubrimiento y un contexto de justificación, y prescindir de la distinción afín entre términos observacionales y términos teóricos. Ninguna de estas distinciones desempeña papel alguno en la práctica científica. Los intentos de reforzarlas tendrían consecuencias desastrosas» (Feyerabend 1975/1992: 152).

Con el problema de la inconmensurabilidad denuncia la falsa dualidad o dialéctica, introducida entre el sujeto y el objeto, entre lo real y lo aparente, entre los hechos y la teoría, entre las proposiciones teóricas y observacionales, entre el contexto de descubrimiento y justificación, entre ciencia y metafísica. En su Tratado contra el Método (1975), escribe: «La separación entre historia de la ciencia, su filosofía y la ciencia misma, se desvanece en el aire y lo mismo sucede con la separación entre ciencia y nociencia» (Cf. Feyerabend, 1975/1992, 32).

Demuestra que la concepción de ciencia del empirismo lógico y del racionalismo crítico al excluir los elementos metafísicos del cuerpo científico, es incapaz de dar cuenta del progreso, la racionalidad y la objetividad científica en 
un cierto tipo de transiciones teóricas. Éstos no ofrecen criterios para discernir si las nuevas teorías se refieren al mismo contenido empírico, si implican un progreso respecto a la anterior (Cf. Feyerabend, 1970/1981b, 152-153), o si es racional su manera de delimitar lo objetivo de lo metafísico (Cf. Feyerabend, 1993/2008, 207, 242-243; 1975/1992, 265-266; 1981h, 16; 1981g, 23, n. 17).

La inconmensurabilidad ontológica demuestra la impotencia de éste modelo de ciencia para justificar la objetividad científica. Pues en él con el principio de consistencia, se sitúa — según Feyerabend- la experimentación o las sentencias observacionales como el fundamento neutro y objetivo que permite corroborar o falsar una teoría. Ahora, la sustitución de ontología que presentan ciertas transiciones teóricas invalida justamente esta posibilidad de falsar o determinar, intersubjetivamente, la verosimilitud de las teorías. Pues si la evidencia empírica o las sentencias observacionales no poseen el mismo sentido o significado en las teorías en competencia, éstas no pueden constituir la base común para corroborar una teoría y falsar otra (Cf. Feyerabend, 1994/1995, 133-134; 1981h, 16).

Aunque Feyerabend denuncia la ausencia de criterios metodológicos universales que justifiquen la elección racional de una teoría, nunca utilizó la noción de inconmensurabilidad para referirse a ella ${ }^{19}$. Pero aun así, como una consecuencia lógica de esta inconsistencia metodológica formula su anarquismo epistemológico. Ante la pretensión del positivismo lógico y del racionalismo crítico de resguardar la racionalidad y la objetividad científica apelando a ciertas exigencias metodológicas, el quehacer científico se presenta —argumenta el epistemólogo vienés - como una empresa caótica y subjetiva. Si el racionalista quiere un principio metodológico aplicable bajo cualquier circunstancia, el único criterio válido — dice Feyerabend con su ironía característica- es el principio 'todo vale' (Cf. Feyerabend, 1970/1999a, 124; 1978/1982, 223, 170-171, 193-194). Por cierto, un principio vacío e inútil. Pero es que justamente la intención de Feyerabend es mostrar por reducción al absurdo las contradicciones y paradojas en las que incurre un racionalista o un positivista lógico al intentar definir la ciencia por un método. Feyerabend pretende mostrar las incoherencias que supone este modo particular de entender, definir y fundamentar en el método la objetividad o la racionalidad científica ${ }^{20}$.

19 Kuhn sí lo hizo. Pero para salvar la racionalidad científica propone como solución un convencionalismo. Para él, a la hora de elegir un paradigma no hay un estándar más alto que el asentimiento o la convención de una comunidad científica relevante (Cf. KuHN, 1970a, 94; 1993/2008, 207). La intención de Kuhn no es negar la racionalidad científica sino presentar como racional una imagen no-formal de ciencia y de objetar simultáneamente la pretensión de Popper, Reichenbach o Carnap de reducir los 'cánones de racionalidad' a un análisis lógico- lingüístico de la ciencia a expensas de los problemas semánticos que ella presenta (Cf. KunN, 1970b, 234, 266-267; (1974), 504.

20 La inconmensurabilidad significa una crisis para el positivismo lógico y el racionalismo crítico que insisten en la distinción entre ciencia y metafísica tal como afirma el Feyerabend en las décadas del 60 y 70. En los 90 el vienés destaca que ésta puede significar un obstáculo 


\section{CONCLUSIÓN}

La doctrina de la inconmensurabilidad significó para el vienés una oportunidad para reducir al absurdo los intentos de definir dialécticamente la ciencia a expensas de lo metafísico. La inconmensurabilidad revela la relación de inconsistencia que existe entre teorías científicas comprehensivas al estar informadas por ontologías recíprocamente excluyentes. Ahora bien, dicha inconsistencia demuestra la imposibilidad de hablar de progreso, realismo y objetividad científica en los términos del positivismo lógico y del racionalismo crítico. Pues estos definen dichas nociones en virtud de un conjunto común de entidades observables. La inconmensurabilidad pone en evidencia cómo cada teoría en función de la ontología que la anima establece un criterio de demarcación particular entre el objeto real y el objeto teórico, entre los elementos objetivos y los subjetivos, entre lo empírico y lo metafísico. De este modo, demuestra la imposibilidad que existe para determinar desde el interior de una teoría científica si en la sucesión de teorías existe realmente progreso, si las teorías tratan con un mismo contenido empírico o si las entidades postuladas por la nueva teoría tienen idéntica referencia ontológica.

La doctrina de la inconmensurabilidad tal cual es formulada por Paul Karl Feyerabend no sólo revela la relación de inconsistencia o la irreductibilidad ontológica entre teorías científicas comprehensivas, sino que concomitantemente denuncia el reduccionismo que suponen determinados modos de entender la ciencia. La inconmensurabilidad, en este sentido puede ser entendida como

para el racionalismo y el relativismo que conciben las culturas como sistemas cerrados e inconmensurables.

En sus estudios acerca de la historia de las concepciones humanas Feyerabend destaca la posibilidad de la inteligencia humana de argumentar y reflexionar al margen de determinados que existe entre los marcos culturales. Su valoración positiva de la inteligencia explica la comunicación y comprensión entre culturas invalidando así la noción de cultura como una unidad inconmensurable propia del relativismo y el racionalismo (Cf. FEYERABEND, 1994/1999, 194). En Provocaciones Filosóficas (1991) hace referencia a esta virtualidad de la inteligencia humana como un motivo que lo alejo de su antigua posición relativista: "Los relativistas sugieren que debemos relacionar todos los juicios acerca de la realidad y la existencia con un marco socialmente dado. Esto parece interesante y, alguna vez, también a mí me lo pareció. Pero hay una gran desventaja: la gente puede argumentar más allá de los marcos de referencia y al margen de ellos. La comprensión puede, durante un tiempo, estar atada a un marco, sin embargo, es capaz de construir puentes hacia los que un relativista estricto tendría que considerar puros disparates. Hay otra desventaja: no todos los marcos dan placer a quienes viven en su seno (placer desde su propio punto de vista). Hace un enfoque bastante concreto para llegar a una cultura viable; viable, de nuevo, desde el punto de vista de los que viven en esa cultura» (FEyerabend, 1991/2003, 61-62).

Esta valoración de la inteligencia pone de manifiesto que Feyerabend nunca negó la posibilidad de una mutua o reciproca inteligibilidad o comparabilidad entre teorías o culturas - como creyeron sus críticos a propósito de su doctrina de la inconmensurabilidad. Éstos no entendieron que la inconmensurabilidad era una objeción, una reducción al absurdo o una objeción a modos específicos de concebir la ciencia y la cultura. 
una reducción al absurdo de las nociones de progreso y realismo científico formuladas por el positivismo lógico y el racionalismo crítico.

$\mathrm{Al}$ destacar la presencia de la metafísica en la ciencia Feyerabend no pretende denostar la ciencia sino demostrar que es falsa la dialéctica que tanto el positivismo lógico como el racionalismo crítico establecen entre ciencia y metafísica. Ahora bien, si esta separación es falsa, la inconmensurabilidad, en un sentido negativo, impide retomar dialécticas o supuestos del positivismo lógico y del racionalismo crítico —o de la epistemología moderna en general一, a la hora de fundar la objetividad o la racionalidad científica. En un sentido positivo, se puede decir que la inconmensurabilidad tal como la formuló Paul Feyerabend es un intento de mostrar la necesidad de buscar una concepción de la racionalidad científica más amplia, omnicomprensiva y capaz de abordar tesis metafísicas.

\section{REFERENCIAS}

Achinstein, P. (1968), Concepts of Science. Baltimore, Johns Hopkins University Press.

Andersson, G. (1984), "¿Son Compatibles falsacionismo y falibilismo?». Estructura y desarrollo de la ciencia. Radnitzky G., Andersson G. (eds.). Madrid, Alianza: 215-232.

Bhaskar, R. (1975), «Feyerabend and Bachelard: Two Philosophers of Science». New Left Review 94: 31-55.

Broad, P. (1979), «Paul Feyerabend: Science and the Anarchist». Science 206: 534-537.

Bunge, M. (2003), Cápsulas. Barcelona, Gedisa.

CARnAP, R. (1978), «La Superación de la Metafísica mediante el Análisis Lógico del Lenguaje.» El Positivismo Lógico. Ayer A. (Comp.) México, Fondo de Cultura Económica: 66-87.

Counihan, T. (1976), «Epistemology and Science - Feyerabend and Lecourt». Economy and Society 5: 470-472.

Davidson, D. (1984), "On the Very Idea of a Conceptual Scheme». Inquiries into Truth and Interpretation. Oxford, Oxford University Press: 183-198.

Devitt, M. (1979), «Against Incommensurability». Australian Journal of Philosophy $57: 29-50$

Devitt, M. (2001), «Incommensurability and the Priority of Metaphysics». Incommensurability and Related Matters. P. Hoyningen. Huene and H Sankey (eds.). Dordrecht, Kluwer: 143-157.

Devitt, M., Sterelny K. (1999), Language and Reality. 2nd. Edition. Oxford, Blackwell.

Dilworth C. (2007). Scientific Progress. A Study Concerning the Nature of the Relation between Successive Scientific Theories. Dordrecht, Springer.

Enç, B. (1976), «Reference of Theoretical Terms». Nous 10: 261-282.

Farrell, R. (2003), Feyerabend and Scientific Values. Tightrope-Walking Rationality, Kluwer Academic Publishers, Netherlands.

FEyerabend, P. (1954/1955), «Review of Wittgenstein's Philosophical Investigations». The Philosophical Review 64: 449-483.

Feyerabend, P. (1955/1981), «Wittgenstein's Philosophical Investigations». Problems of Empiricism. Philosophical Papers Volume 2. Cambridge, Cambridge University Press: 99-130. 
Feyerabend, P. (1958a), «Complementarity». Proceedings of Aristotelian Society, Suppl. Vol. 32: 75-104.

Feyerabend, P. (1958b), «An Attempt at a Realistic Interpretation of Experience». Proceedings of the Aristotelian Society 58: 143-170.

Feyerabend, P. (1958c), «Review of Mathematical Foundations of Quantum- Mechanics. By John von Neumann». British Journal for the Philosophy of Science 8: 343-347.

Feyerabend, P. (1958/1981a), «An attempt at a realistic interpretation of experience». Realism, rationalism and scientific method, Philosophical Papers Volume 1. Cambridge, Cambridge University Press: 17-36.

FEYERABEND, P. (1958/1981b), «Reichenbach's Interpretation of Quantum Mechanics». Realism, rationalism and scientific method, Philosophical Papers Volume 1. Cambridge, Cambridge University Press: 236-246.

FEyerabend, P. (1959), «Comments on Sellars. The Language of Theories». Current Issues in the Philosophy of Science. Symposia of Scientists and Philosophers. Proceedings of Section L of the American Association for the Advancement of Science. H. Feigl- G. Maxwell (eds.), New York, Holt, Rinehart- Winston.

FEyerabend, P. (1960/1981a), «On the Interpretation of scientific theories». Realism, rationalism and scientific method, Philosophical Papers Volume 1. Cambridge, Cambridge University Press: 37-43.

Feyerabend, P. (1960/1981b), «Professor Bhom's Philosophy of Nature». Realism, rationalism and scientific method. Philosophical Papers Volume 1. Cambridge, Cambridge University Press: 219-235.

Feyerabend, P. (1960/1999), «The Problem of the Existence of Theoretical Entities». Paul K. Feyerabend: Knowledge, Science and Relativism, Philosophical Papers Volume 3. John Preston (ed.). Cambridge, Cambridge University Press: 16-49.

Feyerabend, P. (1960/2005), «El problema de la existencia de las entidades teóricas». Scientiae Studia 3: 277-312.

Feyerabend, P. (1961), «Review of Metascientific Queries and Causality. By Mario Bunge». Philosophical Review 70: 396-405.

Feyerabend, P. (1961b), «Review of an Introduction to the Logic of the Sciences. By Rom Harré». British Journal for the Philosophy of Science 12: 245-250.

Feyerabend, P. (1961/1995), "Two Letters of Paul Feyerabend to Thomas S. Kuhn on a Draft of The Stucture of Scientific Revolutions». Hoyningen-Huene P. (ed.). Studies in History and Philosophy of Science 26: 353-387.

Feyerabend, P. (1961/1999), «Knowledge without foundation». Paul K. Feyerabend: Knowledge, Science and Relativism, Philosophical Papers Volume 3, John Preston (ed.). Cambridge, Cambridge University Press: 50-77.

Feyerabend, P. (1962), «Problems of Microphysics». Frontiers of Science and Philosophy: University of Pittsburgh Series in the Philosophy of Science Volume 1. Colodny R. (ed.). Pittsburgh, University of Pittsburgh Press: 189-283.

Feyerabend, P. (1962/1981a), «Hidden variables and the argument of Einstein, Podolsky and Rosen». Realism, rationalism and scientific method, Philosophical Papers Volume 1. Cambridge, Cambridge University Press: 298-342.

FEyeraBend, P. (1962/1981b), «Explanation, Reduction and Empiricism». Realism, rationalism and scientific method, Philosophical Papers Volume 1. Cambridge, Cambridge University Press: 44-96.

Feyerabend, P. (1962/1989), Límites de la ciencia. Explicación, reducción y empirismo. Barcelona, Paidós. 
Feyerabend, P. (1963), «Review of Erkenntnislehre. By Victor Kraft». British Journal for the Philosophy of Science 13: 319-323.

Feyerabend, P. (1963/1999), «How to be a good empiricist: a plea for tolerance in matters epistemological». Paul K. Feyerabend: Knowledge, Science and Relativism. Philosophical Papers Volume 3, John Preston (ed.). Cambridge, Cambridge University Press: 78-103.

Feyerabend, P. (1964/1981), «Realism and Instrumentalism: Comments on the Logic of Factual Support». Realism, rationalism and scientific method, Philosophical Papers Volume 1. Cambridge, Cambridge University Press: 176-202.

Feyerabend, P. (1965), "Problems of Empiricism». Beyond the Edge of Certainty. Essays in Contemporary Science and Philosophy. Colodny R. (ed.). Pittsburg, CPS Publications in the Philosophy of Science: 145-260.

Feyerabend, P. (1965/1981a), «On the «Meaning» of Scientific Terms». Realism, rationalism and scientific method, Philosophical Papers Volume 1. Cambridge, Cambridge University Press: 97-103.

Feyerabend, P. (1965/1981b), «Reply to Criticism. Comments on Smart, Sellars and Putnam». en Realism, rationalism and scientific method, Philosophical Papers Volume 1. Cambridge, Cambridge University Press: 104-131.

Feyerabend, P. (1966), «Herbert Feigl: A biographical Sketch». Mind, Matter and Method: Essays in Philosophy and Science in Honor of Herbert Feigl. Feyerabend P. \& Maxwell G. (eds.). Minneapolis, University of Minnesota Press: 3-13.

Feyerabend, P. (1967a), «The Mind-Body Problem». Continuum 5: 35-49.

Feyerabend, P. (1967b), "Review of Law and Psychology in Conflict». By J. Marshall. Inquiry 10: 114-120.

Feyerabend, P. (1968), «On a Recent Critique of Complementarity: Part I». Philosophy of Science 35: 309-331.

FEYERABEND, P. (1969/1981a), «Science without Experience». Realism, rationalism and scientific method, Philosophical Papers Volume 1. Cambridge, Cambridge University Press: 132-135.

FEYERABEND, P. (1969/1981b), «Linguistic arguments and scientific method». Realism, rationalism and scientific method, Philosophical papers vol. I. Cambridge, Cambridge University Press: 146-160.

Feyerabend, P., Hanson, N. et al. (1970), Discussion at the Conference on Correspondence Rules. Radner M. \& Winokur S. (eds.). Minnesota Studies in the Philosophy Science IV. Minneapolis, University of Minnesota Press.

Feyerabend, P. (1970/1981), "Consolations for the Specialist». Problems of Empiricism. Philosophical Papers Volume 2. Cambridge, Cambridge University Press: 131-167.

Feyerabend, P. (1970/1989), Contra el Método. Esquema de una Teoría Anarquista del Conocimiento. Barcelona, Ariel.

Feyerabend, P. (1970/1999a), "Experts in a Free Society». Paul K. Feyerabend: Knowledge, Science and Relativism, Philosophical Papers Volume 3, John Preston (ed.). Cambridge, Cambridge University Press: 112-126.

Feyerabend, P. (1970/1999b), «Philosophy of Science: A Subject with a Great Past». Paul K. Feyerabend: Knowledge, Science and Relativism, Philosophical Papers Volume 3, John Preston (ed.). Cambridge, Cambridge University Press: 127-137.

Feyerabend, P. (1975/1992), Tratado contra el Método. Esquema de una Teoría Anarquista del Conocimiento. Madrid, Tecnos.

Feyerabend, P. (1976), «Logic, Literacy and Professor Gellner». British Journal for the Philosophy of Science 27: 381-391. 
Feyerabend, P. (1977), «Review of Changing Patterns of Reconstruction». British Journal for the Philosophy of Science 28: 351-382.

Feyerabend, P. (1977/1999), «Rationalism, Relativism and Scientific Method». Paul K. Feyerabend: Knowledge, Science and Relativism, Philosophical Papers Volume 3, John Preston (ed.). Cambridge, Cambridge University Press: 200-211.

Feyerabend, P. (1978/1982), La Ciencia en una Sociedad Libre. Madrid, Veintiuno Editores s.a.

FEYERABEND, P. (1978/1981), «Philosophy of Science versus scientific practice: observations on Mach, his followers and his opponents». Problems of Empiricism. Philosophical Papers Volume 2. Cambridge, Cambridge University Press: 80-88.

Feyerabend, P. (1980/1981), «Mach, Einstein and the Popperians». Problems of Empiricism. Philosophical Papers Volume 2. Cambridge, Cambridge University Press: 89-98.

FEyerabend, P. (1981a), Realism, rationalism and scientific method, Philosophical Papers Volume 1. Cambridge, Cambridge University Press.

Feyerabend, P. (1981b), "Introduction: Scientific Realism and Philosophical Realism». Realism, rationalism and scientific method, Philosophical Papers Volume 1. Cambridge, Cambridge University Press: 3-16.

Feyerabend, P. (1981c), «Introduction: Proliferation and Realism as Methodological Principles». Realism, rationalism and scientific method, Philosophical Papers Volume 1. Cambridge, Cambridge University Press: 139-145.

Feyerabend, P. (1981d), «Introduction to volumes 1 y 2». Problems of Empiricism. Philosophical Papers Volume 2. Cambridge, Cambridge University Press: vii-xii.

Feyerabend, P. (1981e), "Historical Background: Some Observations on the Decay of the Philosophy of Science». Problems of Empiricism. Philosophical Papers Volume 2. Cambridge, Cambridge University Press: 1-33.

Feyerabend, P. (1981f), «The Methodology of Scientific Research Programmes». Problems of Empiricism. Philosophical Papers Volume 2. Cambridge, Cambridge University Press: 202-230.

Feyerabend, P. (1981g), «More Clothes from the Emperor's Bargain basement: a Review of Laudan's Progress and its Problems». Problems of Empiricism. Philosophical Papers Volume 2. Cambridge, Cambridge University Press: 231-246.

Feeyerabend, P. (1981h), Tratado contra el método. $2^{\mathrm{a}}$ ed. Madrid: Tecnos.

Feyerabend, P. (1987a), «Putnam on Incommensurability: Comments on Reason, Truth and History». British Journal for the Philosophy of Science 38: 75-81.

Feyerabend, P. (1987b), «Reason, Xenophanes and the Homeric Gods». The Kenyon Review 9:12-22.

Feyerabend, P. (1987/2005), Adiós a la Razón, Tercera edición. Madrid, Técnos.

FEYERABEND, P. (1989), «Realism and the Historicity of Knowledge». Journal of Philosophy 86: 393-406.

Feyerabend, P. (1989/2000), Diálogos sobre el Método. 2a ed. Madrid, Cátedra.

Feyerabend, P. (1991a), Three Dialogues on Knowledge. Cambridge, Basil Blackwell.

Feyerabend, P. (1991b), Diálogos sobre el conocimiento. Madrid: Cátedra.

Feyerabend, P. (1991/2003), Provocaciones Filosóficas. Madrid, Editorial Biblioteca Nueva.

FEyerabend, P. (1992), «Review of Science and Relativism. Some Key Controversies in the Philosophy of Science. By Larry Laudan». Isis 83: 367-368.

Feyerabend, P. (1993/2008), Against Method. Third Edition. London, Verso.

Feyerabend, P. (1994/1995), Matando el tiempo. Autobiografía. Madrid, Debate S.A. 
Feyerabend, P. (1994/1999), La Conquista de la Abundancia. La abstracción frente a la riqueza del ser. Barcelona: Paidós.

Feyerabend, P. (1994/2000), «Paul Feyerabend: Last Interview». By Jung J. The Worst Enemy of Science? Essays in memory of Paul Feyerabend. J. Preston, G. Munévar and D. Lamb (eds.). New York, Oxford University Press: 159-168.

Feyerabend, P. (1999), Ambigüedad y Armonía. Barcelona, Paidós.

Fine, A. (1975), «How to Compare Theories: Reference and Chance». Nous 9: 51-65.

Finocchiaro, M. (1973), «Review of I. Lakatos and A. Musgrave, Criticism and the Growth of Knowledge». Studies in History and Philosophy of Science 3: 361.

Gellner, E. (1975), «Review of Beyond Truth and Falsehood». The British Journal of Philosophy of Science 26: 331-342.

GentiLE, N. (2007), «El camino de Feyerabend: crítica, proliferación y realismo», Filosofía Unisinos 8: 109-127.

Giedymin, J. (1971), «Consolations for the Irrationalist». British Journal for the Philosophy of Science 22: 39-53.

Grunfeld, J. (1984), «Feyerabend's Irrational Science». Logical Analisys 27: 221-232.

Hattiangadi, J. (1977), «The Crisis in Methodology: Feyerabend». Philosophy of the Social Sciences 7: 289-302.

Hattiangadi, J. (2000), «Two Concepts of Political Tolerance». The Worst Enemy of Science? Essays in memory of Paul Feyerabend. J. Preston, G. Munévar and D. Lamb (eds.). New York, Oxford University Press: 125-147.

Horgan, J. (1993), «Paul Karl Feyerabend: El Peor Enemigo de la Ciencia», Investigación y Ciencia 201: 34-48.

Hoyningen-Huene, P. (2000a), "Paul K. Feyerabend. An Obituary». The Worst Enemy of Science? Essays in memory of Paul Feyerabend. J. Preston, G. Munévar and D. Lamb (eds.). New York, Oxford University Press: 3-15.

Hoyningen-Huene, P. (2000b), «Paul K. Feyerabend and Thomas Kuhn». The Worst Enemy of Science? Essays in memory of Paul Feyerabend. J. Preston, G. Munévar and D. Lamb (eds.). New York, Oxford University Press: 102-114.

Hoyningen-Huene, P., SANKey, H. (eds). (2001), Incommensurability and Related Matters. Dordrecht, Kluwer Academic Publishers.

Hahn, H., Neurath, O y Carnap, R. (2002), "La concepción científica del mundo: el Círculo de Viena». REDES 18: 103-149.

Hume, D. (2004), Investigación sobre el entendimiento humano. Madrid: Istmo.

Kant, I. (2003), Crítica de la razón pura. Buenos Aires, Losada.

KITCheR, P. (1978), «Theory, Theorist and Theoretical Change». The philosophical Review 87: 519-547.

KLimovsky, G. (2001), Las desventuras del conocimiento cientifico. Una introducción a la epistemología. Quinta edición. Buenos Aires, A-Z Editora.

Kordig, C. (1970), «Feyerabend and Radical Meaning Variance». Noüs 4: 399-404.

KRIPKE, S. (1980), Naming and Necessity. Oxford, Blackwell.

Kroon, F. (1985), «Theoretical Terms and the Causal Views of Reference». Australasian Journal of Philosophy 63: 143-166.

Kunn, T. (1970a), The Structure of Scientific Revolutions. $2^{\text {da }}$ ed. Chicago, Chicago University Press.

Kunn, T. (1970b), «Reflections On My Critics». Criticism and the Growth of Knowledge: Proceedings of the International Colloquium the Philosophy of Science, London 1965. Lakatos I, Musgrave A. (eds.). Cambridge, Cambridge University Press: 231-278. 
Kunn, T. (1976), «Theory Change as Structure Change: Comments on the Sneed Formalism». Erkenntnis 10: 179-190.

Kunn, T. (1977), The Essential Tension: Selected Studies in Scientific Traditions and Change. Chicago, University of Chicago Press.

Kunn, T. (1979), «Metaphor in Science». Methaphor and Thought. Ortony A. (ed.). Cambridge, Cambridge University Press: 409-419.

Kunn, T. (1983), Commensurability, Comparability, Communicability. Asquith P. and Nickles T. (eds.) PSA 1982, Volume 2. East Lansing: Philosophy of Science Association: 669-688.

KulKa, T. (1977), «How far does anything go? Comments on Feyerabend's Epistemological Anarchism». Philosophy of the social sciences 7: 277-287.

Laymon, R. (1977), «Feyerabend, Brownian Motion, and the Hiddenness of Refuting Facts». Philosophy of Science 44: 225-247.

Lloyd, E., (2000), «Feyerabend, Mill, and Pluralism». The Worst Enemy of Science? Essays in memory of Paul Feyerabend. J. Preston, G. Munévar and D. Lamb (eds.). New York, Oxford University Press: 115-124.

MunÉvar, G. (1999), «Reviews Symposia: Radical Fallibilism vs Conceptual Analysis: The Significance of Feyerabend's Philosophy of Science». Metascience 8: 216-226.

MunÉvar, G. (2000a), «Preface». The Worst Enemy of Science? Essays in memory of Paul Feyerabend. J. Preston, G. Munévar and D. Lamb (eds.). New York, Oxford University Press: v-vi.

MunÉvar, G. (2000b), «A Rehabilitation of Paul Feyerabend». The Worst Enemy of Science? Essays in memory of Paul Feyerabend. J. Preston, G. Munévar and D. Lamb (eds.). New York, Oxford University Press: 58-79.

MunÉvar, G. (2006), Variaciones filosóficas sobre temas de Feyerabend. Germán Guerrero Pino (Comp.). Caracas, Programa editorial Universidad del Valle.

Nickels, T. (1998), «La Epistemología según Feyerabend». Cinta de Moebio 4: 123-129.

Nola, R. (1980), «Fixing the Reference of Theoretical Terms». Philosophy of Science 47: 505-531.

Oвerheim, E. (2006), Feyerabend's Philosophy. Quellen Und Studien Zur Philosophie. Berlín, Walter de Gruyter.

PaPineau, D. (1979), Theory and Meaning. Oxford, Oxford University Press.

Parsons, K. (1975), «A Criterion for Meaning Change». Philosophical Studies 28: 367-396.

Perovich, A. (1991), «Incommensurability, its Varieties and its Ontological Consequences», en Beyond reason: essays and the philosophy of Paul Feyerabend, Gonzalo Munevar (ed.), Boston Studies in the Philosophy of Science, v.132, Washington, pp. 313-328.

Popper, K. (1972), Conjectures and Refutations: The Growth of Scientific Knowledge. $4^{\text {th }}$ ed. London: Routledge.

Popper, K. (1957), «The Aim of Science» Ratio 1: 24-35.

Popper, K. (1980), The Logic of Scientific Discovery. 4th. ed. London, Routledge.

Preston, J. (1997), Feyerabend. Philosophy, Science and Society. Oxford, Blackwell.

Preston, J. (2000), «Science as Supermarket: 'Post-Modern' Themes in Paul Feyerabend's Later Philosophy of Science». The Worst Enemy of Science? Essays in memory of Paul Feyerabend. J. Preston, G. Munévar and D. Lamb (eds.). New York, Oxford University Press: 80-101. 
Putnam, H. (1965), «How Not to Talk About Meaning». Boston Studies in Philosophy of Science. Volume 2. In Honor of Philipp Frank. Cohen R., Wartofsky (eds.). New York, Humanities Press.

Putnam, H. (1975), Mind, Language and Reality. Philosophical Papers. Volume 2. Cambridge, Cambridge University Press.

Quine, W. (1986), La relatividad ontológica y otros ensayos. Madrid: Tecnos.

Quine, W. (1992), La búsqueda de la verdad. Barcelona: Crítica.

Ribes, D. (1989), «Introducción: Pluralismo teórico y límites de la ciencia». Feyerabend P. K., Límites de la ciencia. Explicación, reducción y empirismo, Barcelona, Paidós: 9-35.

Rossi, P. (1975), «Hermeticism, Rationality and the Scientific Revolution». Reason, Experiment and Mysticism in the Scientific Revolution. Righini Bonelli M. L., Shea W.R. (eds). London, Macmillan.

SANKey, H. (1994), The Incommensurability Thesis. Aldershot, Avebury.

SAnkey, H., Hoyningen-Huene, P. (2001), «Introduction». Incommensurability and Related Matters. Hoyningen-Huene, P., Sankey, H. (eds). Dordrecht, Kluwer Academic Publishers: vii-xxxiv.

Scheffler, I. (1967), Science and Subjectivity. Indianapolis, Bobbs-Merrill.

Shapere, D. (1966), «Meaning and the Scientific Change». Mind and Cosmos. Colodny R. (ed.). Pittsburgh, Pittsurgh University Press: 41-85.

SuPPE, F. (1990), La Estructura de las teorías científicas. Madrid, UNED.

Theocharis, T., Mihalis, P. (1987), Where Science Has Gone Wrong, Nature 329: 595-598.

Van Fraassen, B. (2000), "Sola Experientia? Feyerabend's Refutation of Classical Empiricism». The Worst Enemy of Science? Essays in memory of Paul Feyerabend. J. Preston, G. Munévar and D. Lamb (eds.). New York, Oxford University Press: 28-36.

Watkins, J. (2000), Feyerabend among Popperians 1948-1978. The Worst Enemy of Science? Essays in memory of Paul Feyerabend. J. Preston, G. Munévar and D. Lamb (eds.). New York, Oxford University Press: 47- 57.

Worrall, J. (1978a), «Is the Empirical Content of a Theory Dependent on its Rivals?». Acta Philosophica Fennica 30: 298-310.

Worrall, J. (1978b), «Against too much Method». Erkenntnis 13: 279-295.

Conicet (Consejo Nacional de Investigaciones Científicas y Técnicas)

UnCuyo (Universidad Nacional de Cuyo), Argentina

Teresa Gargiulo

gargiulomteresa@gmail.com

[Artículo aprobado para publicación en noviembre de 2014] 